\title{
NARRACIONES NACIONALES: HOLOCAUSTO Y LA CUESTIÓN JUDÍA EN ISRAEL
}

\author{
Carlos Braverman ${ }^{1}$ \\ Instituto Campos Abiertos, Tel Aviv
}

http://dx.doi.org/10.5209/rev_NOMA.2013.v37.n1.42722

Resumen.- El presente trabajo aborda desde una perspectiva politológica la narrativa nacional israelí centrándose en el análisis discursivo del Holocausto. Analiza la misma señalando que con ella, retoma en Israel la "cuestión judía" e impide la presencia de otra que sea representativa de una nacionalidad común para todas sus identidades societarias más allá de la etnicidad. Profundizando así los derechos civiles y pertenencia al espacio público de todos sus ciudadanos. Es un desarrollo post-sionista del tema.

Palabras clave.- holocausto, cuestión judía, nacionalidad israelí, post-sionismo.

\section{National narratives, Holocaust and the Jewish question in Israel}

Abstract.- This paper addresses, from a political-science view, the Israeli national narrative focusing on Holocaust discourse analysis. The paper analyzes the subject by pointing that with it, it retakes in Israel the "Jewish issue" and prevents the presence of another that is representative of a common nationality for all its societal identities beyond ethnicity. Thus deepening the civil rights and public space (Habermas) belonging to all its citizens. It is a postZionist view of the subject.

Keywords.- holocaust, jewish issue, israeli nationality, post-zionism.

\section{Introducción}

Comenzaré puntualizando en forma precisa y clara que la narrativa nacional israelí por desplazamiento metafórico hasta hoy en día, se entrelaza con la de la diáspora o mejor dicho, con el judaísmo fuera del país. A mi entender es una paradoja; no es casual que el judaísmo fuera de Israel, se enlace a la narrativa mencionada gracias a un entramado discursivo particular. En esta presentación me detendré en explicitar la construcción de las narrativas nacionales y su incidencia en la cultura y percepción de la realidad de los pueblos, como también en la constitución de su carácter (Bhabha Horni K. 2010, De Oto, Alejandro 1995).

${ }^{1}$ Carlos Braverman: Politólogo y Psicólogo, Máster de Ética aplicada a la Salud (Bioética) y Máster en Ciencias Judaicas. Israelí, reside en Tel Aviv, nacido en Buenos Aires, Argentina. Presidente del Instituto Campos Abiertos, una institución de investigación y enseñanza de la ciencia política de inspiración progresista que apuesta decididamente por los derechos civiles y la convivencia. Dedicado a los derechos civiles de su país y solidario con la actuación de entidades similares en el mundo. Su producción científica tiene especial énfasis en la sociedad civil israelí desde una perspectiva post-sionista, la coexistencia judeo-árabe y la paz en Próximo Oriente, Geopolítica del Próximo Oriente, Euro Mediterránea y Euro Asiática. 
Yo soy israelí de orientación postsionista y de acuerdo al criterio de esta escuela, existe una nación de Israel que ocupa un lugar distinto pero metonímico en relación al pueblo judío. Israel es la nación de todos los israelíes judíos o no. Los postsionistas no concordamos con la definición de que es el Estado-Nación del pueblo judío, término que no figura en ningún documento de la legislación nacional, ni siquiera en nuestro Acta de la Independencia. Israel tiene muchas peculiaridades y entre ellas es sobresaliente que no existe la nacionalidad israelí, pero sí la ciudadanía israelí (Braverman C. 2004, 2006, 2009, 2011). De esta forma, los israelíes somos conciudadanos independientemente de nuestras particularidades étnicas, pero no somos connacionales, pues no existe una nacionalidad común para todas las comunidades étnicas que nos vincule al estado. Para el tema en cuestión, abordaremos la narrativa nacional israelí desde múltiples ángulos abarcándola en términos discursivos y centrándonos en el Holocausto. En ese sentido la lingüística nos ofrece el concepto de lo metonímico según Jakobson, tratándose de la sustitución de un término por otro, que presenta con el primero, una relación de contigüidad espacial, temporal o causal. Pero llegaremos finalmente a Jacques Derrida que nos dice mucho más al respecto, con su construcción teórica referida a la relación entre la "différance" y la "difference" a la que volveremos después, ya finalizando nuestro análisis (Derrida Jaques 1968).

Encarar la narrativa del Holocausto en la identidad israelí hoy, es penetrar en una serie de conceptos que vale la pena abordar desde el post-estructuralismo deconstructivista. Lo cierto es que en este articulado de desplazamientos semánticos, el Holocausto entra en la narrativa nacional israelí de la mano del pueblo judío para luego instalarse como propia del país. Así, este hecho histórico se etnitiza y además abarca por desplazamientos metafóricos varios aspectos de la realidad nacional, ofreciendo una lectura a veces muy incorrecta y descontextuada de sus causas (Segev Tom 1992).Se arraiga de esta manera en los valores societarios de Israel, determinando un carácter y una percepción de las cosas que influyen sobre toda su estructura societaria.

Las narrativas nacionales son la construcción de la racionalidad política de la nación como una configuración de estrategias textuales, desplazamientos metafóricos, subtextos y estratagemas figurativas. Configuran de esta forma, un discurso con un determinado lenguaje y trama, que remodela los hechos y objetos conceptuales en sí mismos. Son textualidades que no terminan de conformar una estructura acabada, cuestionando el concepto mítico de totalidad cerrada e inexorable en relación a la cultura nacional.

Son éstas, efectivamente un despliegue amplio y diverso a través del cual construimos un campo de significados y símbolos asociados con la vida nacional. Pero no podemos negar que las historias materiales de los diferentes países y civilizaciones se cruzan con otros imaginarios, utopías y narraciones, con las reflexiones conceptuales y producciones ficcionales de otros pueblos.

Si coincidimos con estas valoraciones, podemos aceptar que cada una de las sociedades se pueda volver a pensar a sí mismas y construyan su futuro a partir de sus experiencias anteriores y de las comparadas con otras entidades societarias. 
Ante todo, las narraciones nacionales paradójicamente cuestionan en sí la etnicidad pura, pues es un entrecruzado de distintos discursos étnicos de procedencias diversas que pasan por una etapa de integraciones distintas, de diversidades de recepción en las diferentes sociedades y funcionalidades variadas de los mismos en cada una de ellas.

Homi K. Bhabha habla de la nación como una forma de narración, de imaginería y de metáfora. Propone trabajar con los tipos de historias que las diferentes instituciones cuentan sobre los orígenes de la misma e insiste en indagar las relaciones entre la idea de nación, la idea de sus minorías y el rol de sus lenguajes y narrativas.

Las naciones son áreas mayoritariamente multiculturales, multiétnicas y multireligiosas en todo el mundo, con un conjunto de nuevas demandas sobre el Estado, a menudo vinculadas por estos motivos, a cuestiones de derechos civiles. Así surge la idea de que la transmisión cultural no es solamente un problema de tradición, como solemos entenderla, sino también un problema de traducción: o sea, el modo en el que tenemos que entender los valores de los Otros en la esfera pública. Estamos entonces hablando también de la adopción de las perspectivas de las minorías, como de la necesidad de enfrentarse con el pasado y no silenciarlo en la configuración de los relatos nacionales. Estos elementos así entendidos, son parte de las luchas de los pueblos por el acceso a la nacionalidad y las mutaciones permanentes del concepto de nación y son centrales en la evolución de éstos y sus integrantes.

Israel es producto de la gesta emancipadora del pueblo judío y del éxito indiscutible de su movimiento de liberación nacional, el sionismo, que se constituyó en un territorio con otras entidades y colectivos étnicos preexistentes. Sin embargo, la narrativa del Holocausto en Israel sobre-acentúa por excelencia, merced a entramados y prácticas discursivas. Predomina étnicamente, la narrativa del judeocidio y no la del crimen contra la humanidad entera, convirtiéndose en central dentro del espacio público.

Se excluye así, desde el discurso público de la narrativa nacional a los segmentos no judíos de la sociedad. Por supuesto que la historiografía israelí no obvia los hechos históricos, por una parte a las víctimas no judías de la tragedia histórica a la que nos referimos y por otra el reconocimiento magnánimo de los Justos entre las Naciones. Acá estamos deconstruyendo el discurso narrativo nacional.

Estas narraciones son constructos, es decir, que responden a una necesidad de lectura y requerimientos nacionales en distintos estadios de la nación. Veamos dos aspectos relacionados al recuerdo del Holocausto y al uso de la palabra Shoá.

\section{Sintáctica, semántica y memoria histórica}

En diciembre de 1948, el Gran Rabinato de Israel, encabezado por los rabinos Herzog y Uziel, decidió que el día de recuerdo de la Shoá, sería según el calendario hebreo, el 10 de Tevet (mes del calendario hebreo), coincidiendo así con el Día de Kadish Universal, el día de Oración por los Muertos 
Desconocidos (Kadish es una oración de recuerdo a los difuntos). La fecha fijada por la ONU, 27 de enero, según el calendario gregoriano, es el día de la liberación del campo de exterminio de Auschwitz - Birkenau (aunque en la práctica no fue una liberación real, pues los nazis ya habían huido del campamento cuando el Ejército Rojo se acercaba al área). En las deliberaciones de la Knéset (parlamento) a principios de 1951, MAPAM (Partido sionista socialista de izquierda, hoy Meretz) trató de determinar el día de conmemoración de acuerdo a la fecha de la sublevación del Ghetto de Varsovia.

El objetivo era claro: hacer hincapié en la resistencia y lucha armada como un modelo para el joven Israel (Dov Levitan. 1989). La lucha armada era lo contrario de la pasividad ante la opresión que significaba la diáspora y la resistencia hasta el final; un símbolo de que el pueblo elige incluso la muerte, si es el único destino posible para no ser sometido. Así, en 1951 se fija de acuerdo al calendario hebreo, el 27 de Nisan como día del "Recuerdo de la Shoá y el Levantamiento de los Ghettos". Conmemorándose después de Pesaj (Pascua Judía), se evita así, la coincidencia con otros temas históricos negativos, relacionándose con algunos positivos para evocar la fecha. Sin embargo, la discusión continúa en una tensión entre laicos y ortodoxos, que consiste en conservar paralelamente el día 10 de Tevet, que no fue anulado y precisar el término exacto de la recordación. Para simplificar, un amplio sector laico como religioso, entendió que no fueron sólo héroes quienes se revelaron, sino también quienes padecieron, murieron o sobrevivieron.

En 1953 se ve positivo desde el Ministerio de Educación, que se coloque la fecha entre Pesaj (Pascua) y el Día de la Independencia de Israel, la Rebelión del Ghetto de Varsovia, que fue el 19 de abril de 1943 y coincidió con la primera noche de Pesaj. Se une así, el simbolismo bíblico de libertad de Pesaj y la rebelión heroica contra el nazi-fascismo, junto a la independencia de Israel.

Las fechas se recuerdan en Israel de acuerdo al calendario hebreo, el día de Pesaj no podía ser elegido por razones obvias. Otro hecho histórico, es que el 20 de abril era el cumpleaños de Hitler y cada tanto hay coincidencias entre el calendario hebreo y el gregoriano.

Pesaj, según el calendario hebreo, es el día 14 del mes de Nisan y resulta que el 19 de abril como regalo de cumpleaños para Hitler, el oficial Jürguenstropp decidió aniquilar el Ghetto de Varsovia.

En 1953 con la Ley de Yad Vashem, se crea una comisión para profundizar el tema y en 1959 queda la fecha decididamente como "Día del Recuerdo de la Shoá y del Heroísmo", en memoria de quienes no se revelaron pero la padecieron, considerándose éste, un hecho valiente (Keneset 1959).

La otra faceta que creo conveniente analizar es la relación entre los términos Shoá y Holocausto. Escuché siempre que es más apropiado decir Shoá y en realidad lo veo como un tema étnico de delimitación del judeocidio, contenido en un crimen de lesa humanidad más amplio.

La palabra se utiliza por primera vez en la Palestina del Mandato, en la publicación judía Davar el 17 de setiembre de 1939. 
En la primera edición del Nuevo Diccionario Hebreo aparece como Shoá lahadut Hagolá, descrita como catástrofe sobre el judaísmo de la diáspora, o sea, literalmente el término fonetizado que utilicé (Wieseltier Meir 1984).

Shoá aparece en la Biblia 13 veces en el Libro de Proverbios, es de connotación religiosa y habla de sacrificio tanto como el término Holocausto. Esta última es también de orden sacrificial y es ofrecer en el "Altar" un animal incinerado en forma total.

La palabra equivalente a Shoá en la mayoría de las lenguas indo-europeas es Holocausto (Holokaust, que tiene origen griego) y como dije, significa completamente quemado, palabra que también se sometió a evoluciones en su historia. En las traducciones de la Biblia se usa para describir la quema de ofrendas.

Antes de la Segunda Guerra Mundial, esta palabra se utilizaba en inglés para describir un incendio, desastre o destrucción. Pero es utilizada por Winston Churchill, en 1929 (Curchill W.1929), para describir la desgracia del pueblo armenio.

Dado que el término Shoá se convirtió en sinónimo de la destrucción de los judíos europeos, el poeta Uri Zvi Greenberg, luchó contra el uso de esta palabra. En su discurso al recibir el Premio Bialik en 1955, dijo que la palabra expresa un desastre inevitable e impredecible, como un desastre natural, y no es acorde con los hechos históricos que evoca. También entiende que no es acorde con la secularización de la nación ya que es un término religioso. En el término Shoá, que indudablemente es religioso, se junta lo inevitable a lo sacrificial por las causas que lo provocan. En este sentido el Rabino Pinchas Menachem Alter, pensó que el término es inadecuado por estos motivos. Afirmó que la palabra aparece en la Biblia como una expresión de la calamidad que recae sobre los impíos. La propuesta alternativa para él, es la palabra Akedah, o sea, ofrenda.

En forma definitiva, el término Shoá es la delimitación del judeocidio y la construcción de una narración específica que explica en el contexto universal el aspecto nacional de la desgracia. Para terminar este apartado quiero aclarar que el día consagrado por la ONU no tiene presencia en el país, pues no es pertinente a la narrativa israelí del Holocausto.

En la población judía del mundo, fuera de Israel, puede crear un tema de desdoblamiento de criterios. En muchas comunidades se conmemoraba y se hace aún, el Levantamiento del Ghetto de Varsovia fuera del contexto de lom Ha Shoá. De cualquier forma, igualmente, siempre se trató de establecer identificaciones con la gesta redencionista del sionismo.

En 2007, el ministro de asuntos de la diáspora Natán Sharansky, encontró la oportunidad de salvar esta cuestión. Estableció la resolución de adosar al día 27 de enero en Israel, la meta de recordar el día universal de la lucha contra el antisemitismo, tema muy propicio para el judaísmo dentro y fuera de Israel. Así, se construyen los registros y particularidades de las narrativas nacionales, con fechas, lecturas, términos y delimitaciones de contenidos étnicos propios, que veremos cómo se van ideologizando. 


\section{El pasado no nos persigue, lo buscamos con pasión}

Dicen que a los judíos nos persigue la historia, y en realidad nos sumergimos discursivamente en un juego pasado-presente que distorsiona las percepciones de las cosas. El pasado condiciona nuestro presente al punto que la obsesión con el pasado histórico, reduce las posibilidades del hoy y disminuye el alcance de las proyecciones nacionales. El mundo se divide así, en víctimas y verdugos y nosotros somos víctimas por antonomasia. El único resultado que se puede esperar entonces, es la desconfianza, el aislamiento y el encierro alienante en uno mismo. Si un episodio en este sentido es paradigmático, no puede ser otro que el Holocausto. Nada ha sido tan traumático y preformó tanto la identidad del pueblo judío. Ningún evento ha sido tan desgarrante para nosotros y nada ha influido tan profundamente sobre nuestra mentalidad como esta catástrofe.

Hay una relación de contigüidad donde Holocausto y sionismo van de la mano en la construcción del pasado y la narrativa nacional. Es un proceso complejo que explicaré de a poco.

El sionismo tomó de la historiografía, los capítulos más apropiados relacionados a sus posturas y metas. Pues para éste, regresar a Sion era volver a una historia de la que el pueblo judío fue enajenado. Entonces, necesitaba mucho más que el sacrificio lógico y razonable para encarar tal empresa, pues era desafiar al mundo entero para retomar esa historia. Es así que toda epopeya nacional del pasado fue buena para reforzar el sentimiento histórico de volver a estar entre los pueblos que construyen su propio destino. Toda cita con la historia del dolor y la resistencia gloriosa, la esclavitud y la liberación, debían ser traducidas a las metas del ideario nacional del sionismo. Esto daba fuerza a la mítica liberadora que el pueblo necesitaba.

Las rebeliones y persecuciones, las cicatrices que nos produjo la historia, encontraron su cenit indiscutiblemente en el Holocausto. Nunca el pueblo judío fue tan humillado, sus libertades cercenadas hasta la deshumanización y su población exterminada en forma tan catastrófica. El Holocausto arrojó unos 12 millones de víctimas y de ellas casi 6 millones eran judías.

La conclusión tras la tragedia era lógica. En ningún lugar se estaría tan seguro como en Israel y éste era el único sitio donde el pueblo judío tendría porvenir (Idith Zertal 2005). Si la historia volviera a repetirse, aquí estaríamos preparados en todo sentido del término y seríamos capaces de defendernos por nuestros propios medios. Nunca deberíamos esperar ayuda de nadie pues no la recibimos antes. Tampoco nos debía extrañar, ya que con su actitud daban sobrados elementos para ello: que los árabes estaban llamados a ser los nuevos exterminadores en potencia.

El razonamiento se completa exhibiendo cuánto nos debe el mundo por este atroz episodio y además su obligación de comprender todo acto de nuestra parte, cuya finalidad sea nuestra seguridad presente y estratégica. Así, el Holocausto es en nuestra sociedad, la médula de un conjunto de narrativas históricas que tienen como objetivo estimular lealtades étnicas, pasando a ser uno de nuestros mitos fundacionales y soporte del imaginario colectivo del país y del pueblo judío que no vive en él. 
El genocidio era un tema tabú en el Israel de los primeros años. Había sentimientos confusos y contradictorios de culpa, vergüenza, cargas morales por haber sobrevivido o no luchado o quedarse en el lugar donde ocurriría la tragedia. No eran pocos los israelíes que despreciaban a las víctimas por su debilidad y preguntaban por qué los judíos no se habían defendido. Había también quienes miraban con altanería a los antiguos deportados y pretendían representar por su parte, al judío nuevo, encarnación misma del sionismo. Los sobrevivientes no tenían un buen lugar en la sociedad y si lo encontraban, era a través de la mimetización sobre-acentuada con el nuevo judío, con el sabra (natural del país) y con la imagen del pionero duro y arriesgado.

Ben Gurión sabía interpretar las necesidades históricas del pueblo y el juicio a Eichmann marcó el inicio de un proceso por el cual el Holocausto dejó de ser un traumatismo (Segev Tom 2010). Se convirtió entonces en memoria nacional institucionalizada, llegando a ser finalmente un elemento esencial de la identidad de Israel, de su cultura y de su vida política. Al principio, Holocausto era sinónimo de sumisión vs heroísmo. Luego, con el juicio, la empatía hacia los supervivientes aumentó a través del impacto de los testimonios personales y superó este esquema instalándose en la población en forma positiva. En principio el tándem antitético era cámara de gas o rebelión de los ghettos.

El juicio creó una comunidad de identidad histórica en el pueblo y una continuidad vigente hasta el presente, que sustenta a la identidad nacional. Hay una cadena de eslabones entre el holocausto, la rebelión y el Estado de Israel al punto de que el final de la Shoá en el país, no significa liberación de los campos de exterminio, sino el retorno a Israel. En el Acta de la Independencia de 1948 dice: "La catástrofe que recientemente azotó al pueblo judío la masacre de millones de judíos en Europa - fue otra clara demostración de la urgencia por resolver el problema de su falta de hogar, restableciendo en Eretz Israel el Estado Judío, que habrá de abrir las puertas de la patria de par en par a todo judío y conferirle al pueblo judío el status de miembro con igualdad de derechos en la familia de las naciones. Sobrevivientes del holocausto nazi en Europa, como también judíos de otras partes del mundo, continuaron inmigrando a Eretz Israel superando dificultades, restricciones y peligros, y nunca cesaron de exigir su derecho a una vida de dignidad, de libertad y de trabajo en su patria nacional".

Así, el primer jefe del ejecutivo logró con esmerada genialidad cerrar un ciclo e instalar el Holocausto en la médula de la sociedad y a Israel prácticamente como tributario del mismo. Terminó de construir la narrativa que enlazaba a la tragedia nacional, como el eslabón que precedía al hito redencionista del sionismo. De las cenizas de un pueblo, nacía un futuro inquebrantable de constante reafirmación y futuro para ese mismo pueblo. Las diásporas que se concentraban en Israel, como el caso de los judíos provenientes de países árabes, que no vivieron el Holocausto, comenzaron a asumirlo como propio, considerándose también sobrevivientes del genocidio, el Holocausto era ya parte de la narración nacional israelí. 


\section{La cuestión judía en Israel, habitar en la ciudadela inexpugnable}

De esta manera, la diáspora y lo que representaba ella para el sionismo, o sea, su antítesis, se instala en el imaginario del campo societario israelí con representaciones entrecruzadas y contradictorias. Comienza el proceso donde vemos un Israel que se judaíza cada vez más y se des-israeliza proporcionalmente a la primera parte del binomio. La cuestión judía del pasado con sus contradicciones y conflictos se re-instala inesperadamente donde debía surgir la identidad alternativa del nuevo judío del futuro. Si existía algo que entonces se deseaba con ansia, era dejar la diáspora y la impotencia que representaba, como también sus entramados discursivos muy ajenos al proyecto de un Israel ya establecido.

El cambio de actitud de Israel con respecto a la Shoah refleja evoluciones como las señaladas anteriormente y un cambio radical del sionismo en cuanto a su proyecto para la normalización de la vida judía. El éxito del sionismo en ese sentido hubiera debido ser la superación de la mentalidad de diáspora, que mostró desde entonces una continuidad y causalidad directa con ella bajo otras formas y circunstancias.

La conclusión es que no estamos acá para construir una vida judía distinta, estamos para defendernos, para habitar una ciudadela inexpugnable donde defendernos de los Otros que irremediablemente siempre nos odiarán. Sin embargo, sionismo fue siempre buscar el futuro y el porvenir, conformar una nación soberana donde las diásporas se unieran en el acto constituyente de la misma y transformarnos a nosotros mismos en el camino hacia estos objetivos. Pero descubrimos que por el camino elegido, el pasado sigue ocupando nuestro presente y ocluyendo nuestro futuro, entonces continuamos reclamándole al mundo y seguimos siendo potenciales víctimas de él.

Por esta vía, el sionismo se convirtió, más que en un movimiento creador, en una religión agregada al estado, cuando antes mostró ser portador de capacidad de un cambio radical personal y colectivo en la percepción judía del mundo.

Fue desde entonces el sionismo una religión secular más preocupada por mantener conectadas entre sí las distintas diásporas con la centralidad de Israel, que hacer de ella una nación donde se integraran adecuadamente todos sus colectivos étnicos.

El impacto del Holocausto en mi pueblo es obvio y entendible. Pero analizo otro aspecto, que es la funcionalidad de la narrativa estructurada sobre el tema. Acá estoy analizando, estoy deconstruyendo un esquema narrativo y vale la pena que agregue un poco de mi propia experiencia.

Si llegué desde Buenos Aires a Israel, es porque fui sionista y buscaba en esa vida nueva una faceta distinta del ser judío, que en nuestro pensamiento era sinónimo de convertirnos en un pueblo normal, con país, lengua, territorio y nada que lo diferenciara del resto de las naciones. Digo bien, naciones, pues se trataba que como pueblo, ejerciéramos la capacidad constituyente de conformar un Estado para ordenar jurídicamente la nación judía y en ese acto dotarla de una existencia soberana, a partir de lo cual seríamos israelíes junto a todos los que habitaban, de acuerdo a lo resuelto entonces por la ONU, lo 
que nuestro Acta de la Independencia denominó inmediatamente como Israel y no lo delimitó excluyentemente a lo judío.

No buscábamos ser un pueblo elegido, ni menos ser el faro que ilumina a las naciones del orbe y base de la ética para el mundo. Nuestra mentalidad estaba caracterizada por el hecho de que nada le debíamos al mundo y nada nos debía éste a nosotros. La imagen del pueblo sufriente era el contraste del pionero constructor del futuro que anhelábamos ser con el trabajo de la tierra y el renacer de una cultura hebrea no diaspórica. Como postsionista, hoy busco lo mismo, ya con una vida conformada y realizada en este país, al que considero mi única patria.

En ese sentido fue siempre mi deseo, que muchos más judíos hubieran entendido así el destino de nuestro pueblo y se hubieran sumado a realizar su vida en Israel. Como también hoy preferiría que las diásporas, justamente porque existe el Estado de Israel, no se definieran como tales, pues el concepto de dispersión perdió vigencia. También es obvio que no están "dispersos" en relación a Israel, ya que somos israelíes quienes nos acreditamos como ciudadanos de él.

En el SXXI ser postsionista significa buscar ese clima de normalidad que también buscábamos antes, o sea, ser un país donde trabajar, vivir en paz, crecer y sobre todo ser fundamentalmente israelíes. Un país donde sea israelí el judío, el árabe que vive en él y por supuesto todo miembro de cualquier colectivo que habite en su seno.

Yo estoy analizando cómo se construye una narrativa nacional, en este caso muy puntual y hemos visto que es necesario su ideologización e institucionalización. Si se ideologiza el Holocausto en relación a la meta histórica del sionismo, reeditando la cuestión judía en Israel, como constructos de una narración nacional medular israelí, poco se contribuye a afianzar una adecuada a la historia del país. Es decir, que sea funcional a sus necesidades de consolidación y desarrollo presentes como entidad nacional autónoma y soberana.

\section{La necesidad de olvidar, un reto existencial}

Las circunstancias políticas de Israel se vieron conmovidas por distintos hechos, tal vez un gran impacto equivalente a la guerra de Yom Kipur, fue la primer Intifada. La sociedad se vio interpelada por primera vez desde su interior y tuvo que cuestionarse muchos aspectos de su propia ética.

La metaforización del Holocausto no faltó tampoco a la cita y fue cuando el filósofo Yehuda Elkana publicó su famosa carta en la edición del 2 de marzo de 1988 del diario Haaretz, cuyo artículo se titula "The Need to Forget" (Elkana Yehuda 1988).

Elkana desarrolla una crítica muy pormenorizada sobre el excesivo peso del pasado en la comprensión e interpretación de los hechos presentes.

Dice que la sociedad israelí en sus relaciones con los palestinos experimenta una crisis existencial alimentada por la particular interpretación de las lecciones 
del Holocausto y la disposición a creer que el mundo entero está contra nosotros y que somos la eterna víctima. Él ve en esta concepción de las cosas la victoria trágica y paradójica de Hitler. No es el único que escribió sobre la cuestión de dilucidar si Hitler venció o hay que vencer a Hitler todos los días. De la experiencia de Auschwitz, existen dos sectores en el judaísmo, especialmente en Israel, en relación al aprendizaje ético de ese drama histórico. Muchos afirman que "esto nunca debe volver a ocurrir" y otros afirman que "esto no debe sucedernos de nuevo". Es evidente que la segunda es etnicista y no universalista como la primera.

Elkana dice que cualquier filosofía de vida alimentada exclusiva 0 principalmente por el Holocausto, conduce a consecuencias desastrosas.

El tema es el peso del pasado en el presente; la cuestión es que el pasado no mate al presente enterrando también al futuro. No es negar la importancia de la historia y la memoria colectiva como parte inseparable de cualquier cultura, pero no se puede convertir en el elemento dominante para determinar el futuro de la sociedad y el destino de las personas.

Elkana no se equivoca cuando dice que la mitología política del Tercer Reich se basó en las lecciones del pasado con el fin de construir el futuro, explotando el sufrimiento de la historia como un argumento político. Agrego que esto se llama "mitopoiésis". La mitopoiésis es el proceso de creación colectiva de mitos. Se trata de construir mitos e historias que generen un contexto y un mapa de valores pasibles de ser instituidos en símbolos, que se articulen de modo coherente con los ya existentes en una comunidad. En el caso nazi, se evocó toda una mitología identitaria funcional a sus premisas para interpretar el presente y delimitar el futuro.

Elkana invoca a Thomas Jefferson cuando dijo que la democracia y la adoración del pasado son incompatibles. La democracia fomenta el presente y el futuro, nos recuerda.

Yo agrego que el exceso de pasado nos puede enfermar de identitarismo y conculcar el trabajo para el futuro del conjunto societario, que son los graves problemas de hoy, del presente complejo y multicultural que es Israel.

Elkana en su carta, no ve mayor amenaza para el futuro del Estado de Israel, que el Holocausto haya penetrado sistemática y enérgicamente en la conciencia pública de los israelíes.

Hay que contextuar su carta, en una coyuntura donde Israel se debía interrogar sobre su eticidad, su conducta a seguir con las demandas palestinas y la forma de actuar sobre esta población. La metaforización del Holocausto como hecho existencial, predispone a interpretar el presente, como parte de una constante del pasado.

El pedido de Elkana es preciso, hay que aprender a olvidar. Lo que no quiere decir borrar de la memoria colectiva; quiere decir no actuar de acuerdo a experiencias del pasado, sino a las exigencias del presente. 


\section{Recordar no es un pacto con el pasado}

La eticidad que Israel reclama en cuanto a las consideraciones que exige por esta catástrofe histórica, es también exigida a Israel como a todo otro país. Un verdadero boomerang.

En las definiciones más clásicas de las escuelas teóricas de las relaciones internacionales, la Teoría Realista, altamente pragmatista y diríamos "egoísta del estado", impone al mismo, actuar ante todo por su propio bienestar. La eticidad con la que se aborda a Israel como contrapartida a sus exigencias, lleva a que reciba críticas que otros estados no reciben cuando obran de acuerdo al criterio realista comentado.

El pedido de eticidad surge también desde amplios sectores de su población como consecuencia de la narrativa que estamos analizando; la respuesta del establishmet entonces, es reforzar la misma.

Desde la guerra de Suez- 1956- en adelante, hubo cambios fundamentales en la sociedad, donde la exigencia de eticidad surge desde el mismo campo israelí. La Guerra de los Seis Días y la retención de territorios como su posterior colonización, la Guerra del Líbano I en 1982, las Intifadas I y II, son ejemplos donde la desmedida eticidad que implica invocar reiteradamente el Holocausto, juega en contra de las políticas de Israel.

El 29 de octubre de 1956, durante la Guerra de Suez, en la aldea árabe de Kfar Kassem, un grupo de pobladores, que desconocían las medidas de seguridad y no comprendían la voz de alto de una patrulla israelí, fue atacado con un saldo importante de víctimas fatales.

El poeta Natán Alterman se preguntó, cómo pudo ocurrir; pero el sentimiento de la población fue que no somos mejores que los demás y esto es lo que expresó Alterman en un escrito muy recordado (Alterman N. 1956).

En los hechos bélicos-políticos mencionados, muchos se negaron a cumplir órdenes, pues quedó claro que el cumplimiento de órdenes tiene un límite. Un alto porcentaje de los entrevistados en esas circunstancias declaró que la influencia de la historia del Holocausto determinó su conducta (The Nation 2012).

La carta de Elkana toma más sentido. Él pide que aprendamos a olvidar como un recurso retórico que nos libere de actuar por la presencia perpetua del pasado en nuestras vidas. Todos los israelíes sabemos que la respuesta oficial fue integrar aún más esta narrativa.

Se instala en la sociedad otra articulación discursiva que es el Zajor (Deut. 25.17-19): palabra que significa "recuerda". Estos versículos dicen:

«Recuerda lo que te hizo Amalec en el camino, cuando salisteis de Egipto...no olvidarás esto». Está claro que Amalec encarna a todos los enemigos del pueblo judío. En este caso, Amalec es todo aquel que de acuerdo al establishment, es una amenaza y por sobre todo, es apoyar cualquier acción que éste entienda como fundamental para la seguridad.

Siempre la memoria histórica jugó un rol fundamental en la vida judía. 
El término zikarón, "memoria", aparece más de 20 veces en el Pentateuco y también allí hay más de 300 variaciones del término zajor, "recuerda" (Rab.Emanuel Feldman, 2010). También Rab. Y.Hayin Yerushalmi trabaja las distintas metaforizaciones posibles del "Zajor" (Rab. Y.Hayin Yerushalmi, 1996). Pues, como dijo críticamente Elkana, hay quienes dicen:"no debe ocurrirnos nunca más a nosotros"; este concepto determina en el imaginario social, que hoy es como ayer y será como mañana. De esta forma debemos recordar siempre que se trata de "ellos" y de "nosotros".

La Nakba (tragedia en árabe), es la narrativa palestina en relación a la conformación del Estado de Israel y tampoco está ajena a la metaforización del Holocausto (Said Edward 1998- Rothschild Matthew 2009). Desde los negacionismos preliminares y la disminución de su valorización histórica, se produce una metonimia singular con la participación de destacados intelectuales palestinos.

Edward Said se pronuncia en términos donde exhorta a comprender el sufrimiento judío como valor universal para la superación de la barbarie. Dice que es un puente para que se entiendan dos comunidades sufrientes y encuentren una forma de superar el desentendimiento. Culmina con un Ilamado a no utilizar mutuamente entre sí este hecho como elemento político trasladándolo al conflicto entre ambos pueblos.

A mi entender, acercar histórica y conceptualmente la Nakba al Holocausto, es una impostura de la que son tan marcadamente irresponsables y faltos de criterio sensato, tanto algunos sectores israelíes como otros palestinos. En el campo israelí no pocos intelectuales de la izquierda se suman a aceptar esta metaforización en función de la eticidad. Creo que las distancias, sentidos y consecuencias de ambas catástrofes históricas son abismales. En nada aporta, tomar este camino para una narrativa transaccional de acercamiento de sendas experiencias históricas para el entendimiento mutuo y la coexistencia entre los pueblos, justamente por lo que estamos analizando.

El desplazamiento metafórico llega al punto que desde su fundación en 1948, Israel prohibió informalmente la música de Wagner por su uso en la propaganda nazi, antes y durante la Segunda Guerra Mundial.

Los desplazamientos llegan más lejos aún. En 2011, el parlamentario Uri Ariel (entonces partido Unión Nacional, sector de derecha que representaba a los colonos) presentó un proyecto de ley que tiene por objeto prohibir el uso de la palabra "nazi" o palabras que suenen parecido, o epítetos asociados con el nazismo y el Tercer Reich tanto como sus símbolos pertinentes, salvo que sean usados con fines didácticos y no para difamar a terceros. La Asociación de Derechos Civiles en Israel, manifestó que:

"la libertad de expresión implica el derecho a decir cosas difíciles que podrían ser incluso molestas. Esto incluye el derecho de hacer uso retórico de imágenes provocativas y duras. La cuestión de la legitimidad social de la utilización simbólica del Holocausto en el discurso público y político es sin duda una cuestión que merece un debate público, sólido y libre, no es una cuestión que debe ser manejada a través del derecho penal" (ACRI 2012). 
Es obvio, que este proyecto de ley tiene como finalidad controlar el discurso público en Israel, su contenido y tono. También es peligroso el control del contexto: en qué se puede y cómo se pueden mencionar ciertos términos.

Lo claro es que el uso de los términos nazi y Holocausto pueden ser así instrumentados caprichosamente. Nazi puede ser siempre el Otro, el no judío.

La cuestión se remonta a los años 50, el entonces opositor Menajem Beguin, era frecuentemente apodado de fascista por la conducción del bloque parlamentario del MAPAM (Partido Socialista que conformó con otros el hoy Partido Meretz). Con su clásico tono demagógico, con la mano en el corazón, les pedía a sus críticos que no le acusen de fascista porque los judíos sufrimos mucho con los fascismos. Entonces, Beguin era el mentor de muchas políticas que sí podemos catalogar de fascistas.

Este proyecto de ley fue presentado el 14 de noviembre de 2011. El Comité Ministerial de Legislación votó a favor de este proyecto y pasó la primera lectura parlamentaria de las tres obligatorias (2012).

En febrero de 2012, un grupo de pacifistas fundó una página informática en una conocida red social llamada Im Tirtzú-Fascists. Im Tirtzu ("Si lo queréis"), organización extraparlamentaria cuyo nombre se basa en una frase de Theodor Herzl (Haaretz 2012). Persigue a las ONGs pacifistas que promueven la laicidad, la oposición a la colonización y el cambio en la sociedad civil. Esta organización demanda judicialmente a los pacifistas por entender que el epíteto los ofende y tergiversa sus metas.

Se pidió el testimonio del Prof. Zeev Sternhell, por ser un experto israelí reconocido internacionalmente en temas sobre fascismo. Su conclusión es que la ideología de Im Tirtzu y sus acciones, contienen elementos fascistas.

En su declaración, el profesor Sternhell dice que no hay una definición clara e inequívoca de un movimiento fascista y que no hay movimiento en la historia que tenga todos los componentes para su definición. Éste ve una clara expresión del pensamiento fascista en las referencias de Im Tirtzu a la nación como cuerpo orgánico. Otros signos de pensamiento fascista señalados por el académico en referencia a esta organización son: el punto de vista exclusivista de corte occidental y el sentir que Israel vive una emergencia que requiere una acción extrema para luchar contra los "traidores". Aparentemente los desplazamientos metafóricos llevan a pensar que los fascistas siempre son los Otros. La narrativa del Holocausto implica que un israelí judío no puede ser nazi-fascista, es más, el denunciante de esta situación, puede ser un traidor a su pueblo y ofender la historia del mismo.

\section{Estoy solo y no hay nadie en el espejo}

Esta genial frase de José Luis Borges, me permite considerar otras perspectivas en el análisis crítico que estoy desarrollando. En el momento de recordar la tragedia histórica, el pueblo judío estuvo solo, mal acompañado y considerado tardíamente. 
Cuando Auschwitz comenzó a necesitarse para otras construcciones discursivas-políticas, la cuestión se transformó en parte de otro desplazamiento metonímico, ahora fuera del ámbito judío.

Durante la Segunda Guerra mundial, el tema era de los nazis y de los Aliados. En la guerra, cada uno tuvo su propia perspectiva y los judíos no contábamos; todos sabían la existencia de ese horror, pero las operaciones de guerra tenían un sentido muy ajeno a terminar con él.

Finalizada la guerra, los entendimientos geopolíticos que acompañan la nueva etapa, hacen imposible una reconsideración seria y real de los hechos.

Alemania era un nuevo aliado de EEUU, Europa estaba imposibilitada de una revisión profunda, dado los colaboracionismos y otros hechos que no se destacan por una postura ética pertinente.

Después de la década de 1960, hay un cambio radical por el paso del tiempo y la reconsideración de algunos temas geopolíticos. En los años 80, la literatura sobre el Holocausto llega como tal a la TV, al cine, y se escriben hasta Best Sellers, ya no sólo expuesto como hecho bélico de la Segunda Guerra. Desde los años 90, con el fin de la Europa dividida, el Holocausto es una referencia universal. Durante muchos años los antiguos Aliados prefirieron no pensar en los sufrimientos de los judíos durante la guerra. Hoy sin embargo Auschwitz es la cuestión ética central de la Segunda Guerra Mundial.

Acá llegamos al punto de reconsiderar el tema del mal absoluto y nuevamente el rol de las narrativas y prácticas discursivas.

El eje discursivo predominante establece que Hitler fue el mal absoluto, que su horrenda experiencia no se repetirá, que es el sinónimo por antonomasia del mal y creo que no es así.

Estoy convencido que hay que vencer a Hitler todos los días, ¿acaso puede el mal medirse, tiene dimensión, existe una medida para concebir que después de ella no puede superarse?

La respuesta es no, pues conocimos las luchas de pos-guerra hasta hoy día y cómo se recrea el mal, no lo puedo ver mensurable, la industrialización de la muerte no tiene límite y posee muchos formatos.

En 1944 los Aliados sabían de los gaseamientos en Auschwitz-Birkenau. Desde el 20 de agosto al 13 de septiembre de 1944, la fuerza aérea de los Estados Unidos bombardeó el complejo industrial de Auschwitz-Monowitz, a menos de 5 millas de las cámaras de gas. No obstante los Estados Unidos no bombardearon ni las cámaras de gas ni las vías de tren usadas para transportar prisioneros (The United States Holocaust Memorial Museum 2012).

La RAF con el plan del conocido mariscal Arthur Harris, un estratega de los ataques nocturnos sobre civiles alemanes, no tocó una sola pieza de la maquinaria del horror y la infraestructura militar de la misma (Longmate, Norman 1983).

Dice Tony Judt:

Por una parte, el exterminio de judíos llevado a cabo por los nazis se presenta como un crimen singular, un mal que ni antes ni después tuvo su paralelo, un 
ejemplo y una advertencia ¡Nunca más! Pero por la otra hoy invocamos ese mismo mal ("único") en muchos casos distintos que están lejos de ser únicos. Estos últimos años tanto políticos como historiadores y periodistas utilizaron la palabra "mal" para designar crímenes masivos y genocidios perpetrados en todo el mundo: de Camboya a Ruanda y de Chechenia a Sudán. A menudo se evoca al propio Hitler para designar la naturaleza y las intenciones de dictadores modernos que competen al "mal": se nos dice que en todas partes hay otros tantos "Hitler". Y lo que es más, si Hitler, Auschwitz y el genocidio judío encarnan un mal único, ¿por qué se nos advierte constantemente contra el hecho de que esos crímenes podrían repetirse en cualquier lugar, o que están a punto de repetirse? (Judt Tony 2007).

Auschwitz en la narrativa expuesta, es la división simplificada entre el bien y el mal, es el mal potenciado al máximo insuperable frente a quienes están opuestos a él. Son todos los enemigos. Mediante los aportes que nos brinda el post-estructuralismo, podemos entender cómo los poderes fácticos construyen y re-construyen según sus necesidades históricas coyunturales en tanto tales. Este campo de exterminio, de acuerdo al análisis que expongo es la justificación moral, el discurso eticista de los poderes fácticos; ellos entre otras cuestiones gracias a Auschwitz no son el mal, pues está en ese campo de exterminio como emblema indiscutible de éste.

La historia dice que poco hicieron justamente contra el terrible judeocidio en su momento y no hablo sólo de EEUU que sería una simplificación patética. Hablo con claridad de los poderes fácticos de ayer y de hoy.

La Resolución de la ONU 60/7de 2005: Recordación del Holocausto, llega tarde para las víctimas y los sufrientes implicados (los sobrevivientes y sus pueblos), pero oportuna para los poderes fácticos.

En las actas de la 60 Asamblea General de la ONU, donde se aprobó por unanimidad este tema tan sensible, no muestra a los miembros, en una posición tan firme y contundente. La iniciativa impulsada en principio por EEUU e Israel, es discutida arduamente, en la misma, ningún país se opone, incluso algunos abiertamente conflictivos con Israel. Sin embargo, muchos manifiestan que deben estar incluidos o tratados otros genocidios o crímenes de guerra.

Finalmente, se acepta como dije antes por unanimidad y se toma como fecha de recuerdo de la tragedia, el 27 de enero, día de la liberación de Auscwitz (Actas ONU, 2005).

A pesar de mi enunciado crítico sobre el tema, entiendo por supuesto, los beneficios de ciertos deslizamientos discursivos que ofrece esta resolución y los espacios que abre en las posibilidades de atravesar los entramados narrativos del desastre histórico y de su historiografía. No es ajeno para mí que permite abordar las responsabilidades conscientes y no conscientes de múltiples actores históricos de gran responsabilidad y de un segmento acrítico que incurrió en involuntarias pero criminales actitudes por comisión u omisión de hechos. En este caso los actos anuales, los programas escolares y la difusión del tema, son de fundamental importancia para estos objetivos. 


\section{La filosofía dialógica como abordaje de la historia}

El autoritarismo nazi-fascista es perfectamente descrito por Hanna Arendt. Dice Arendt que los campos de exterminio no fueron propiamente invento del régimen pero sí, el emblema institucional totalitario. En los campos de exterminio no sólo se esclavizaba o se denigraba al ser humano, se le extraía su humanidad misma (Arendt Hanna 1987, 2000). Se eliminaba la persona jurídico-moral y física de las víctimas. Es decir, que se las extraía de la sociedad sin ningún cargo legal aceptable fuera de una sociedad autoritaria, se las separaba del mundo en forma semi-clandestina, y por último, con la institucionalización de la tortura permanente, se destruía al ser humano reduciéndolo así a cosa.

El fenómeno lo termina explicando, cuando muy bien puntualiza, que el campo era la base experimental de una futura sociedad que debía nacer.

Es cierto que cuesta pensar en una repetición de esta historia, pero también no es difícil pensar que la historia se sigue repitiendo en otros formatos. Es nuevamente el dilema de decir que Hitler venció, o debemos seguir venciendo a Hitler.

Fue el judeocidio más científico de la historia y el crimen contra la humanidad más industrializado en su rendimiento.

Es posible así, entender la narrativa israelí judía y que en Israel siga siendo Iom Ha Shoá la fecha del recuerdo y no el día que instituyó la ONU, que prácticamente no tiene presencia en nuestra vida. Pero también es necesario entender como decían Martin Buber y Franz Rosenzweig (Buber Matin 1973, Rosenzweig Franz 1997), que es imposible concebir las cosas sin una concepción relacional entre ellas. Es decir, que sin los Otros no hay existencia, lo que pone en duda esta teoría, es hasta qué punto es posible una desmedida delimitación étnica o nacional de esta tragedia.

Existen muchos motivos para considerar a Israel como el Estado-Nación del pueblo judío. Para mí como para todo postsionista no lo es, conforma la Nación de Israel, de los israelíes. La ideologización constante del tema, la perduración del sionismo en la agenda pública estatal después de la independencia y la interpretación discrecional del Acta de la Independencia del mismo, son elementos suficientes para mantener activa y pendiente esta cuestión.

A pesar del pluralismo al que invita el Acta de la Independencia, la naturaleza judía de Israel tiene obvias implicaciones como sus símbolos nacionales, la supremacía de la tradición judía en sus instituciones públicas, al igual que los feriados nacionales y días conmemorativos correspondientes al mismo. El gobierno mantiene el carácter judío de Israel a través de la legislación y la democracia étnica como sostén privilegiado.

A diferencia del judaísmo, el ser israelí estaría asociado a una conexión ciudadana vinculada a las fronteras del Estado de Israel y hablamos entonces, de una identidad adquirida.

Los aportes del postsionismo en la superación de la etapa etno-nacional son innegables. El sionismo es considerado así, como algo que se convierte en redundante después de la construcción de Israel. Recordemos que el mismo 
Ben Gurión sostuvo que con el establecimiento del Estado, el rol del sionismo había concluido.

\section{Postsionismo vs la cuestión judía}

De esta forma, la perspectiva post-sionista no es una nueva fase histórica, sino más bien un nuevo punto de vista, una nueva epistemología que subvierte y socava el punto de vista lineal y esencialista del nacionalismo. Es la exposición de las múltiples identidades y una expresión de la heterogeneidad que el sionismo trató de homogeneizar. Es la deconstrucción del sujeto y de las narrativas que desdibujaron presencias y generaron exclusiones en la construcción de la israelidad. En su enfoque habermasiano, representa una perspectiva post-nacional de la ciudadanía israelí e incluso del patriotismo constitucional israelí, desvinculado del esencialismo pre-político y orientado hacia las condiciones procidementales del derecho desvinculado de lo etnocultural (Habermas 1985, 1997, 2000, 2007).

Este tipo de nacionalismo, basado en un marco actual y común de vida de todos los colectivos del país, en vez de hechos históricos devenidos en mitos fundacionales, puede superar la tensión entre la identidad judía de Israel y las bases para la constitucionalidad del Estado. En este punto de vista, para ser plenamente democráticos, Israel debe convertirse en un Estado de sus ciudadanos, en lugar de un estado de la etnia.

Una pregunta específica en el enfoque post-moderno es la relación entre la identidad israelí y la judía. En la vertiente de Habermas, el post-sionismo es pasible de establecer una distinción e inter-relación clara entre la identidad israelí y la judía.

Orientado hacia el constitucionalismo, prestigia la autonomía de la israelidad como base para la legitimación democrática. Entonces, se trata de articular lo judío a los otros aspectos de la identidad de Israel, sin menoscabo de ello y sin negar la razón histórica de ser del país.

Habermas no soslaya en los términos acuerdistas aspectos importantes para las mayorías, recordando también que es moral toda norma que devenga de la participación de todos y se puedan reconocer en ella.

Así, la narrativa comentada extensamente es muy limitante, funcional en aspectos determinados, pero con resultados muy negativos en otros.

Israel no es tributaria directa del holocausto, sí es cierto que el judeocidio sensibilizó al mundo.

Las acciones de las formaciones armadas irregulares judías en el Mandato Británico, habían ya vencido a un Reino Unido que salía debilitado de la Segunda Guerra. La acción diplomática de la Agencia Judía que oscilaba entre Washington, París y Moscú, aseguraba de por sí un éxito en la decisión de la ONU.

El Holocausto fue una historia en la que todos podíamos haber hecho más contra su fatalidad. No creo que debemos exigirle nada al mundo y por 
consiguiente, entonces, éste no debería exigirnos nada a nosotros. La cuestión judía siempre fue la interrogación de la sociedad y de los judíos sobre su situación y lugar en ella. Fue el tema de la identidad judía en la dispersión.

Algunos entienden que la sociedad es la que ha empujado al judío a la situación de tener que hablar de una "cuestión judía", y a ella le corresponde por lo tanto, encontrar una solución al problema que ella misma ha creado. Para muchos judíos es un tema personal a encarar cómo viven su judaísmo en las diferentes sociedades.

Acá en Israel, la narrativa del Holocausto tal cual la comenté, retoma la cuestión judía. Pero ya consideré por qué está fuera de tiempo en la etapa histórica que vive el país. Podría agregar que la diáspora no tiene una narrativa propia de éste por razones que antes expliqué, que es para ésta, la misma narrativa que fue muy funcional para Israel; el Holocausto termina con el regreso a Israel y éste es el centro de la vida judía. La funcionalidad discursiva de esta narrativa para Israel, lo es también para la diáspora.

La narrativa del Holocausto así como la analicé, poco aporta a la israelidad. La nuestra debe estar basada en la construcción de una nación y la integración de sus componentes y no en el pasado de la diáspora. De lo contrario, se judaiza y no se israeliza nuestra sociedad.

Debemos construir una narrativa que nos asegure la identidad que necesitamos como israelíes, y me refiero no sólo a los judíos. La narrativa nacional israelí no puede obviar el binomio Atzmaut (independencia de Israel)Nakba (catástrofe para los palestinos) entre otros ítems, es el más complejo, pero no el único. Creo con convicción, que la elaboración de la síntesis permitirá entre otras cuestiones pendientes, facilitar la israelidad de los ciudadanos árabes que decidieron que Israel es su país. Esto último, independientemente de la futura y plena existencia del Estado Palestino. No me cabe duda que será un debate difícil y que tampoco será ajeno al republicanismo y patriotismo constitucional habermasiano que mencioné.

No creo equivocarme que el tema estará presente cuando sea el turno del debate hacia la constitucionalidad que el país se debe a sí mismo. Estoy convencido que ya estamos demasiado acompañados por el pasado, que debemos buscar un futuro para hacer viable nuestro presente.

La religión judía fue la primera en santificar el tiempo y no los espacios, los ciclos en el judaísmo son fundamentales pues el tiempo pudo acompañarnos en los distintos devenires de expulsiones y consecuentes peregrinajes. Cada etapa de la gesta del pueblo se inscribe en el calendario hebreo y se recrea como un ciclo que se repite sin fin. Existe un precepto que nos ordena vivir cada hecho de nuestro nacimiento en tanto pueblo, como si fuera hoy, para reforzar su contenido. Así, Pesaj en cada y distinta época, es el tiempo de la libertad, pues cada uno de nosotros está saliendo de Egipto en ese momento. Esta interpretación tiene como fin que el pasado nos oriente a construir el futuro, no a atraparnos en él, recordar para emprender un futuro, no para verlo desde el pasado.

Différence es un neologismo, homófono de la palabra francesa différence (diferencia) propuesto por Jacques Derriday significa que algo no se 
puede simbolizar porque desborda la representación. Derrida se vale del hecho que el verbo différer significa en francés tanto posponer como diferenciar. Él menciona el diferimiento, pues las palabras y los símbolos nunca pueden resumir plenamente lo que significan y sólo pueden ser definidos mediante nuevas palabras de las que difieren. Así, el significado es siempre pospuesto y diferido en una cadena interminable de signos significantes. Otra cuestión que aborda el filósofo en la misma tesitura, es que de esta forma nos referimos siempre a la presencia de lo que fue presente, o la presencia de lo ausente. Todas las narraciones nacionales tienen a mi entender algo de lo expuesto por Derrida, nos muestran siempre la presencia de lo que fue presente, la presencia de lo ya ausente. Nunca se pueden abordar en su plenitud y su sentido se desplaza en interminables signos significantes que nunca pueden terminar de anclar.

Yo trabajo para que esto nos permita acceder al porvenir, no para que la historia nos atrape, no es cuestión de vivir cultivando el pasado.

Creo que Hitler no venció, por eso hay que vencerlo todos los días y eso se hace trabajando para un futuro de democracia con bienestar e igualdad para todos. No creo que esto se logre en una boda con el pasado, al que por cierto venero con pasión. Yo también salí de Egipto y en el camino a Canaán me transformé en pueblo con el resto de los que emprendimos el Éxodo. Cada Pesaj recuerdo como si fuera hoy ese momento y sé que cada uno de nosotros estuvimos ahí. Lo recuerdo para seguir construyendo el futuro y no para interpretar el presente desde la historia; ya salí de Egipto hace mucho tiempo y vivo en Israel. Zajor (recuerda) debería ser esto, recordar y no ser capturado por el recuerdo, no ser jamás su prisionero. Es lo que aprendí como judío, pero ante todo como portador de humanidad, como ser humano.

\section{Bibliografia}

*Homi K. Bhabha Nación y narración entre la ilusión de una identidad y las diferencias culturales ISBN 978-987-629-141-5octubre de 2010 SXXI

*de Oto, Alejandro: Viaje, etnicidad y narracciones: los límites y los movimientos Estudios de Asia y África: México, D.F.: El Colegio de México, Centro de Estudios de Asia y África: v. 30, no. 2 (97) (mayo-ago. 1995), p. 257274

*Derrida, Jaques: "Différance", conferencia pronunciada en la Sociedad Francesa de Filosofía el 2.7 de enero de 1968, Theorie d'ensenble (col. Quel. Ed. de Seuil 1968).

*Segev Tom, The Seventh Million: Los israelíes y el Holocausto, Keter Publishing House, Jerusalén, 1992, pp 424.

*Zertal Idith,Israel's Holocaust and the Politics of Nationhood, Cambridge University Press, 2005.

${ }^{*}$ Churchill Winston, The Aftermath, 1929, p. 158. 
*Levitan Dov, ¿Por qué tres días para conmemorar el Holocausto? Edición semanal interna, hebreo, División interdepartamental de Ciencias Sociales Colegio Académico de Ashkelon 1989, hebreo.

*"Memorial del Holocausto Ley de Levantamiento de los Ghettos de 1958", Knesset, Volumen 24, 18 de junio 1958 pp 2119, hebreo.

* "Enmienda Día del Recuerdo 1959", a la Knesset, Volumen 26, marzo 10, 1959, pp 1385 1390, hebreo.

*Wieseltier Meir, "Palabras", Los años 60 en pocas palabras 1984, p 189, hebreo.

*Yerushalmi Y.Hayin Zakhor: Jewish History and Jewish Memory - 1996 (University of Washington Press, Seattle 1982).

*Longmate, Norman. The Bombers: The RAF offensive against Germany 19391945. London: Hutchinson, 1983. ISBN 0-09-151580-7

*Arendt, Hannah. The Origins of Totalitarianism. Books LLC. May 14, 2000. Paperback, Language English, ISBN: 1443239968.

*Arendt, Hannah. Eichmann in Jerusalem: A Report on the Banality of Evil. Viking Press. 1987. Hardcover, , ISBN: B000LEXNFO.

*Zertal Idith,Israel's Holocaust and the Politics of Nationhood, Cambridge, University Press, 2005.

*Truche Pierre: Le crime contre l'humanité in Les cahiers de la Shoah $\mathrm{n}^{\circ} 1$, 1994. ISSN 1262-0386. Les Éditions Liana Levi, 1994.

*Buber Martin ¿Qué es el hombre?, Fondo de Cultura Económica, México, 1973.

*Rosenzweig Franz, "La Estrella de la Redención” Ediciones Sígueme 1997.

\section{Artículos}

*Braverman Carlos, Post-sionismo, neo-sionismo y la batalla por un país con justicia distributiva e igualdad. Jevratenu, Ed. Instituto Campos Abiertos, Tel Aviv, 2004 hebreo.

*Braverman Carlos Estado Judío y Democrático o Nación Israelí. Jevratenu, Ed. Instituto Campos Abiertos, Tel Aviv, 2006 hebreo.

*Braverman Carlos Israel y la ciudadanía de baja intensidad, Jevratenu, Ed. Instituto Campos Abiertos, Tel Aviv, 2009 hebreo.

*Braverman Carlos Postsionismo e identidad israelí vs Estado Judío y Democrático, Jevratenu, Ed. Instituto Campos Abiertos, Tel Aviv, 2011 hebreo.

Publicaciones Online

*Yehuda Elkana, The Need to Forget "Haaretz" Israeli Newspaper on the 2nd of March $1988 . \quad$ Online: http://www.einsteinforum.de/fileadmin/einsteinforum/downloads/victims_elkana. pdf 
*Ruth Linn - Ilan Gur-Ze'ev Holocaust as Metaphor: Arab and Israeli Use of the Same Symbol DOI: 10.1207/s15327868ms1103_2Ruth Linn \& Ilan GurZe'ev, pages 195-206 HaifaUniversity http://www.tandfonline.com/doi/abs/10.1207/s15327868ms1103_2\#preview 2009

*Matthew Rothschild, September 2, 2009, The Holocaust and Palestine http://www.progressive.org/wx090209.html

*Said Edward Israel-Palestine: a third way Le Monde diplomatique English 1998 http://mondediplo.com/1998/09/04said

*The United States Holocaust Memorial Museum COPYRIGHT (c) UNITED STATES HOLOCAUST MEMORIAL MUSEUM, WASHINGTON, D.C. accecible online: http://www.ushmm.org/wlc/es/article.php?Moduleld=10005762

*Segev Tom Eichmann united the Jewish people. Haaretz Isreli Newspaper http://www.haaretz.com/print-edition/news/eichmann-united-the-jewish-people$1.262725^{\star}$ Judt Tony November 30,2007 , on the occasion of the award to Tony Judt of the 2007 HannahArendt Prize http://www.nybooks.com/articles/archives/2008/feb/14/the-problem-of-evil-inpostwar-europe/?pagination=false FEBRUARY 14, 2008 THE NEW YORK REVIEW OF BOOKS

*Rab Emanuel Feldmann: Crucial lessons for humanity to remember always, 2010 http://www.aish.com/jw/s/Does_the_Holocaust_Still_Matter.htm

*Jerusalem court starts debating meaning of Fascism as Im Tirtzu sues activists Haaretz 2012 http://www.haaretz.com/print-edition/news/jerusalem-court-startsdebating-meaning-of-fascism-as-im-tirtzu-sues-activists-1.412357

*Voices of Conscience in Israel The Nation 201 http://www.thenation.com/article/166123/voices-conscience-israel

*Alterman N. Davar" "The Seventh Column" -Alterman in newspeak Haaretz 2011 http://www.haaretz.com/weekend/week-s-end/alterman-in-newspeak1.387178

*ACRI Knesset passes laws prohibiting use of Nazi symbols Haaretz http://www.haaretz.com/news/national/knesset-passes-laws-prohibiting-use-ofnazi-symbols-1.406725 